\title{
Change Agents and Resilient Practices: The Power of Symbolic Capital in a Post-Merger Integration Context
}

\author{
Dragos Vieru \\ TÉLUQ University \\ dragos.vieru@teluq.ca
}

\author{
Suzanne Rivard \\ HEC Montréal \\ suzanne.rivard@hec.ca
}

\author{
Ulrika H. Westergren \\ Umeå University \\ ulrika.westergren@umu.se
}

\author{
Simon Bourdeau \\ UQAM \\ bourdeau.s@uqam.ca
}

\begin{abstract}
This study analyzes the interactions among mandated change agents within a post-merger integration context and examines the implications of their practices as they attempt to engage with others in a cross-boundary information system implementation project. We examine the case of the Metropolitan Healthcare Center, where three previously independent centers were merged into one, and follow the individuals who were appointed to ensure the integration of a new, mutual information system across the three center sites. We draw on a practice perspective and the notion of symbolic capital to shed light on post-merger practices and their outcomes. Our analysis suggests that one of the change agent's practices of boundary consolidation through influence tactics were legitimized through discourses of authoritative knowledge and 'group-making'. This facilitated the construction of symbolic boundaries between the merging parties, thus contributing to the resilience of pre-merger practices despite the planned intention to create change.
\end{abstract}

\section{Introduction}

Post-merger integration (PMI) refers to the process of value-creation that organizations anticipate from a merger [16]. Despite the benefits that mergers can yield, high failure rates have been reported [28, 33]. Indeed, the PMI phase is often beset by problems such as high levels of employee stress [10], job dissatisfaction and employee resistance [27,24], or higher turnover intentions [29].

While employees' resistance to PMI changes has been considered one of the main causes of mergers' failure to live up to their initial goals [24], the literature on strategy stresses that examining how change agents - that is individuals mandated by upper management to implement PMI changes and to ensure that these changes follow the strategic rationale $[12,18]$ - interpret and implement change and how they construct their work environment can shed light on some of the unintended outcomes of a change process $[1,26]$.

When change agents are involved in change initiatives across boundaries such as those called for in post-merger integration, they are involved in boundary spanning, defined as a practice that links an organization or a business unit to its environment, including other organizations with which it interacts [23]. Their role, as change agents in such a context, is to reconfigure, if not remove, boundaries so that collaborative work will flow efficiently. In order to realize their change objectives, change agents often rely on influence tactics and use of networks [14], coercion, and authoritative or supportive persuasion [21]. The idea is that PMI change agents will promote boundary spanning by using their relational power within their respective organizations.

A merger often implies the implementation of new information systems (IS) that will span across previously independent organizations [27]. Research has shown, albeit not in a PMI context, that the success of IS implementation initiatives is highly dependent on effective collaboration among individuals [25]. Given the special context of the PMI process, collaboration initiatives are likely to be challenging since the actors involved abide by different local, social and cultural rules emerging from different pre-merger organizational context delineated by pre-merger boundaries and actors' interpretations of what is "at stake" for them [31]. In such a context, the mandated change agents are important organizational advocates for implementing the new system.

However, despite targeted efforts, PMI change processes sometimes fail or lead to unintended outcomes. In fact, it has been shown that even change agents might sometimes resist change and obstruct collaboration efforts [18], despite their pronounced mission to promote change. To shed more light on this phenomenon and explore the relationship 
between post-merger practices and their outcomes we investigate the questions: How do change agents use influence tactics and what are the implications of these practices on the outcomes of cross-boundary IS projects in a PMI context?

Drawing on a practice perspective [2], we analyze change agents' utilization of symbolic capital during the process of post-merger boundary reconfiguration. We conduct a case study within a large metropolitan healthcare center (MHC) that resulted from the merger of three previously independent hospitals. The case is an IS implementation project - from project inception until the system was put in production - carried out over a period of six years: the ambulatory appointment information system (AAIS).

\section{The Practice Perspective and the Power of Symbolic Capital}

Within a given field of practice, agents are distinguished by their status, which is characterized by the accumulated amount of three types of individual capital: economic capital (e.g., personal finance), cultural capital (e.g., expertise) and social capital (based on professional relationships) [2]. Agents can transform either of their capitals into a fourth type, symbolic capital, which may give them the ability to claim relevant knowledge or authoritative knowledge [31]. According to Suchman [25, p.142], authoritative knowledge can be described as a knowledge that is "taken to be legitimate, consequential, worthy of discussion, and useful for justifying actions by people engaged in accomplishing some concerted task". Thus, symbolic capital represents the ability to successfully define reality, thereby shaping the practices of others. For one to acquire symbolic capital, one must experience a process of valuation [2]. In cross-boundary collaboration, which is based on the possession of intellectual, social, and economic capital, an agent's claims of authoritative knowledge must be perceived as 'valid' by the audience, who then attributes legitimacy to the agent. In this vein, the positions agents occupy in a given field and the forms of capital they possess matter, but only to the extent that others in the situation value those positions and forms of capital, converting them into a source of symbolic power.

The differences in meanings and interests between fields of practice are usually negotiated by boundary spanners [4]. Boundary spanners may be nominated or may emerge, but to be effective they must be viewed as legitimate participants in the fields of practice being spanned and recognized as negotiators between fields, and they must be motivated to act as negotiators [18]. However, as Levina and Vaast [18] found in their study, some boundary spanners may use their formal power to obstruct the collaboration efforts across boundaries and resist change.

\subsection{Discursive Legitimation Strategies as Explanation for Unintended Outcomes}

Discursive legitimation represents symbolic capital that emerges through a political rationalization process of downplaying one's own interest and making explicit the opponent's interest. In this view, legitimacy or its opposite term, illegitimacy, are created in relation to discourses that provide the frames of mind with which individuals make sense of particular situations. In the context of PMI, legitimation, as creating a sense of positive, acceptable status quo and delegitimation, as creating a negative sense of change, may represent resistance to change initiatives [28].

Discourses are persistent systems of thought (including ideas, attitudes, beliefs and practices) that enable and constrain what can be thought, said and done [3]. In this study, we analyze two legitimation discourses: 1) authoritative knowledge discourse [25]; and 2) 'group-making' discourse [3]. We operationalize them as symbolic capital-based discourses [2] and as such, we view them as discursive strategies through which senses of legitimacy or illegitimacy are created.

The discourse of 'group-making' is characterized by "logic of existence by delegation" or "by proxy" [3]. The social reality, according to Bourdieu [3], can be objectively divided into different social spaces, the occupants of which are said to be sharing objective similarities and thus constitute groups or classes. But, Bourdieu argues, no real group exists without some agent naming the group and therefore bringing it into existence. Thus, a group exists or emerges when there are agents capable of imposing themselves, who are authorized to speak and act officially in its name. In this view, the production and reproduction of groups by creating symbolic boundaries is seen as necessary during agents' participation in struggles over the classification and representation of communities and represents an act of resistance to any action that may affect the group structural integrity. Symbolic boundaries are conceptual distinctions made by organizational members to acquire power status, monopolize resources, categorize people and practices and generate feelings of similarity and group membership [15]. 


\section{Methodology}

This research was conducted as a case study, which represents a research approach which focuses on understanding the dynamics existing within single settings [9]. In this way, the researcher is able to identify emerging dimensions of the phenomenon and the relationships that emerge from the study through the researcher's interaction with the organization members within their context.

\subsection{Research Context}

We focus on one specific IS project, the development of an ambulatory appointment information system (AAIS) that was expected to enable the post-merger integration of separate but similar site-based departments (ambulatory services). The selected organization was the Metropolitan Healthcare Center (MHC - not the real name), a Canadian tertiary care teaching institution. The MHC is the result of a 'merger of equals' of three independent teaching hospitals with over 1 million patient visits per year: two Adult hospitals (the Downtown and the Midtown) and a Pediatric hospital. While the term 'acquisition' refers to the purchase of a target organization for absorption into the acquiring organization, in a 'merger of equals', merging parties are considered full partners and when PMI approaches do not reflect the pre-merger promises, the result may be dissatisfaction and distrust.

The merger was initiated with the goal of creating a mega-hospital to provide modern health care by implementing a "best practices" approach for coordinating care. In the pre-merger context, the MHC hospitals developed their own sets of applications, both for the clinical-administrative and administrative application portfolios. Also, each hospital center had its own medical patient index and patient ID card, used several and separate patient scheduling systems, managed beds and emergency rooms according to the internal site perspective, operated its own and distinct order entry and result reporting system and produced statistics specific to the patient stays within the specific center sites.

According to the MHC IS Strategic Plan, the post-merger application portfolio needed to adapt to a seamless, integrated organization that would result from the redesign of the business processes. The patients would have a single number and ID card linked to a single record number used by all MHC centers. According to the IS Project manager, "because of the expected magnitude of the process redesign", keeping legacy systems in use was considered to be an ineffective cost option. At the outset of the AAIS project, the ambulatory services managers from the three different centers were thus enlisted in a project team to act as change agents and enable the development and implementation of the mutual system.

\subsection{Data Collection}

We conducted semi-structured interviews with the persons who had held key roles in the project (see Table 1). A total of 12 interviews (six interviewees in two rounds of interviews) were performed. They were based on a pre-designed protocol and lasted between 30 and 45 minutes each. All interviews were recorded and transcribed. The interviews were supplemented by archival documents (e.g., strategic planning sessions, management presentations, emails, and communications planning), which offered a source of triangulation for the themes that emerged from the interview data. Due to their sensitive content and the data privacy laws, we were allowed to consult these documents only on site. These documents were used in three ways.

Table 1. List of Interviewees

\begin{tabular}{|l|l|l|}
\hline $\begin{array}{l}\text { Function at the outset } \\
\text { of the project }\end{array}$ & $\begin{array}{l}\text { Referred to } \\
\text { in the text as }\end{array}$ & Center \\
\hline $\begin{array}{l}\text { Ambulatory Services } \\
\text { Manager (ASM) }\end{array}$ & $\begin{array}{l}\text { Midtown } \\
\text { manager }\end{array}$ & Midtown \\
\hline ASM & $\begin{array}{l}\text { Downtown } \\
\text { manager }\end{array}$ & Downtown \\
\hline ASM & $\begin{array}{l}\text { Pediatric } \\
\text { manager }\end{array}$ & Pediatric \\
\hline IS Project manager & IS Manager & MHC \\
\hline IS Specialist & & MHC \\
\hline IS Specialist & & MHC \\
\hline
\end{tabular}

First, the various reports and presentations were used to assist us in putting together the project's chronology, including identifying the dates of important events and decision junctures. Second, emails and management presentations were used to formulate and refine interview questions. Third, reports and meeting minutes were used to corroborate and validate interview reports. Each interview was semi-structured with both a structured interview guide and room for unstructured questions. In a few instances, when clarifications were required, followup questions were asked via phone or email. Interview questions focused on understanding, from the participant's standpoint, the history of the project collaboration practices, claims of relevant knowledge, differences in system's functionalities 
between the initial and the go-live phases of the project, as well as the personal implications of the merger. When no new information was revealed during interviews, data collection was terminated.

\subsection{Data analysis}

The interview data were analyzed in an iterative process [9] by cycling between data, emerging themes, and relevant literature to develop a deeper understanding of the dynamics of the cross-boundary collaboration during the IS implementation process. First, we created a provisional "start list" of codes (Table 2) informed by our theoretical perspective prior to the interviews. Second, the interview transcripts were read carefully and relevant portions highlighted. The highlighted portions were then keyed into the database into a field called "evidence" as chunks of rich text. All of the transcripts were coded using the preliminary set of codes. In line with our theory-building objective, we remained open to emerging themes, which can lead to the creation of new codes and categories when appropriate [20]. Thus, the key category of boundary consolidation was created. Following this, we entered a new coding iteration, going back to the transcripts and coding them anew to take into account the new category. We relied on authors' agreement and consensus to reconcile any coding disagreement.

Table 2. Coding Categories

\begin{tabular}{|l|l|}
\hline Initial Coding List & Differences in practices \\
\cline { 2 - 2 } Categories & Fields of practice \\
\cline { 2 - 2 } & Boundaries \\
\cline { 2 - 2 } & $\begin{array}{l}\text { Cross-boundary collaboration } \\
\text { practices }\end{array}$ \\
\cline { 2 - 2 } & IS design \\
\cline { 2 - 2 } & Individual capital \\
\cline { 2 - 2 } & Role of boundary spanners \\
\cline { 2 - 2 } & Symbolic discourses \\
\hline Emerging Category & Boundary consolidation \\
\hline
\end{tabular}

\section{Findings}

From the outset, teamwork was organized by peerbased collaboration without a formal project manager from the user side. The three managers soon realized that they needed someone to follow up on decisions after each meeting and act as a liaison with the IS developers. The Pediatric center manager thus emerged as the leader of the group because she was the only one having worked in an IS implementation project before. The other team members found her charismatic, experienced and respected in her work community. Retrospectively, the Pediatric manager also saw herself, in the context of the project, as being: "the spearhead ... the catalyst... the person that is the glue that holds this together and gives direction, keeps people on track". (Pediatric manager) She considered herself a leader and found it normal to take the lead in the implementation process.

Team meetings involved exchanging clear information about the needs of each member's own department in order to effectively negotiate and convince the others of the need for specific system features. The outcomes of these discussions were often a compromise representing the result of various claims of legitimate knowledge made by the manager from the Pediatric center based on her past experience in implementing clinical administrative IS. During this period, the three managers were going back to their centers and consulting with key players in the clinics to make sure that the system that they were trying to put together was in fact reflective of what the clinics' needs were. As the project progressed, the Pediatric manager successfully negotiated changes to the software functionality, tailoring it to suit the needs of the Pediatric center. While one of the goals of the pre-merger MHC strategic plan was to implement a common set of administrative practices, at the end of AAIS project, MHC ambulatory services presented two different sets of practices: one, at the Pediatric center, that preserved pre-merger norms and another, at the two Adult centers, that can be described as new practices common to both entities.

\subsection{Theme 1: The Emergence of Symbolic Capital}

Change agents in cross-boundary collaboration are expected to bring expertise specific to their role to the endeavor at hand. For example, in a new product implementation effort, participants bring distinctive expertise to shape the features, performance, and production processes for the new product [5]. Their distinction is accentuated by the fact that agents on each side of the boundary have accumulated different kinds of capital [2] and their respective fields of practice may be significantly different. Each of the three ambulatory service managers, who had worked for several years in the three respective pre-merger hospitals, were highly regarded by the upper management, and had accumulated distinct knowledge, experience and expertise in terms of managing patient registration, appointments, waiting lists, etc. In the first few months of the project, the three managers had to share their knowledge of the ambulatory procedures used in each of their centers. 
To their surprise, they realized that, even though those site-based procedures seemed similar, their execution varied from one field of practice to another.

At the outset of the project, the three team members were not aware of significant differences between their practices due to the fact that they never had to interact before.

"In the first three months, that knowledge transfer, in terms of how they [the other centers] do it versus how we [Downtown center] do it, it was a very novel thing because you tend to think the way you do things is the entire universe right and so it's been a wakeup call to discover that there are all kinds of different ways of approaching the same process, the same basic function" (Downtown manager)

Not only had they never met before, but they also had never been involved in the development of a similar IS.

"What we discovered was the way that the clinics work at the Adult hospitals versus the Pediatric was very, very different [...] In fact a lot of the differences between procedures... came along many times as a result of discussions around the user group table during the development [...] As far as the Pediatric, it is black box. I know a little bit because I take my children there when they are sick, that's it" (Midtown manager)

Even though they were all officially employees of the MHC, the fact that they were coming from different hospitals and were now supposed to share knowledge and develop a common system presented some initial challenges:

"So it took us a little while to do that because there was a group of people that had never met each other before so figuring out a way to work together was initially a bit of a challenge" (Midtown manager); “Actually we didn't know each other. We had never met. I met [Downtown manager] there; I had never met him before. You thought of yourself as, I'm site specific" (Pediatric manager)

The case data show that the three center managers, who were appointed as change agents and boundary spanners by the upper management, possessed significant amounts of social and intellectual capital accumulated in time within their fields of practice at the outset of the implementation process. Even though the change agents had never met before, they were aware of the other agents' hierarchical position and had heard of their professional reputation within their respective fields of practice. They went through a quick process of valuation of each other's accumulated individual capital at the outset of the project.
"[The Pediatric manager] was very quickly taken on a leadership role... We all respected the hell out of her. [The Downtown manager] was always in there advocating for her clerks." (Midtown manager)

"[The Midtown manager] was very good at arguing the pros and cons of a certain functionality." (Pediatric manager)

"I would say [Midtown manager] for his experience of how things worked at Midtown because he's been there a lot longer than me." (Downtown manager)

However, only the Pediatric manager tried and successfully converted her accumulated intellectual and social capitals into symbolic capital to claim authoritative knowledge.

"Information Systems is my field of competence, so it's very easy to talk to a programmer. I provided a good sort of leadership in that sense [...] I had fought for getting it for the Pediatric center, because there's nothing worse than implementing a new system and losing functionality of the things you had before [...] I'm sure they [at the Adult centers] don't really care what system we have due to the fact that the Pediatric clinics don't need to communicate any patient data to the Adult clinics. (Pediatric manager)

While during the project meetings most issues were solved by an immediate consensus or through persuasion based on trade-offs, in some rare instances the Pediatric manager used her accumulated symbolic capital to unilaterally make a decision. For example, when she asked for a specific modular interface to be built into the system, the Downtown manger didn't understand its utility for her center's clinics. The Pediatric manager notes that she tried to argue for her need but to no avail:

"[Downtown manager] wouldn't let go. She couldn't understand why we needed that, and at one point it was like, look, I'm going to get it for the [Pediatric], whether you understand or not, I'm getting it" (Pediatric manager).

\subsection{Theme 2: Resisting Change by Boundary Consolidation}

The Pediatric manager engaged in symbolic discourses of 'group-making' that would present her as an authorized voice to represent the Pediatric population and its needs with respect to the ambulatory clinics. She described the members of the Pediatric field of practice as being completely different from the members of the other centers of the MHC and referred to herself as ' $w e$ ' and ' $u s$ '. During the system implementation at the Pediatric center she tried hard to classify her field of practice (Pediatric ambulatory services) as being unique compared to the 
other two fields of practice in front of the other two change agents and to refute any idea of integration.

"I think in terms of like structure and follow up and whatever, I provided a good sort of leadership in that sense. [...] I have to say, we being, the Pediatric, probably influenced a lot because the whole project actually came from a needs analysis that we had submitted [...]. They moved Orthopedics from the Downtown and centralized it at the Midtown. I think they've redone some of their management structure in terms of that. But that didn't affect us. So the Pediatric will remain independent" (Pediatric manager)

Although the mandate of the change agents was to entice the others to collaborate and alter the premerger boundaries, the Pediatric manager focused all her efforts on what was "at stake", protecting the existing boundaries between her field of practice and the rest of MHC. She used her symbolic capital to promote the idea that Adult centers and the Pediatric center were engaged in business processes that were so different that they could not be integrated into the same system. A specific type of data confidentiality was one of her main arguments that the Pediatric center was different from the two Adult centers and due to its procedural and clinical differences her center should never be integrated with the rest of the MHC.

"You have convictions about the way certain things should function or not. For example, confidentiality of information is a big topic... For example, 'I'm calling, I'm in the middle of a divorce; I don't want my husband to know my phone number'. So, the big question is how do you block that information, are you able to flag it? So obviously for us in Pediatric it's a huge issue because we deal with that kind of situation. On the adult side, not that much.” (Pediatric manager)
On the one hand, the Pediatric manager thought that the Pediatric center should keep its clinical practice independence, while the main administrative functions, such as Finance and HR would be fully integrated in the structures of the MHC. Pediatric manager was convinced that the development of the new AAIS had more to do with implementing a system that would make the management of the ambulatory services more efficient, than with the merger. Thus, she tried to convey the message that it was in the Adult centers' interest to concentrate on their own clinical data.

"I'm pretty sure they [Adult centers] don't really care what system we have due to the fact that the Pediatric clinics don't need to communicate any patient data with the clinics on the Adult side of the MHC." (Pediatric manager)

By using a mixed symbolic 'group-making' and claims of relevant knowledge that skewed the existing power dynamics within the project team, the Pediatric manager was able to reproduce the Pediatric hospital's old, resilient practices into the system configuration. Therefore, at the end of the implementation project, the resulting common AAIS had two database instances, one for the Pediatric center, which enabled the preservation of the premerger practices and another one for the Adult centers that enabled new common administrative practices. At the end of the project, the boundary between the Pediatric and the rest of the MHC centers in terms of ambulatory services were still up instead of having been erased, which would have been the logical outcome of the PMI process.

Figure 1 illustrates this process of boundary consolidation.

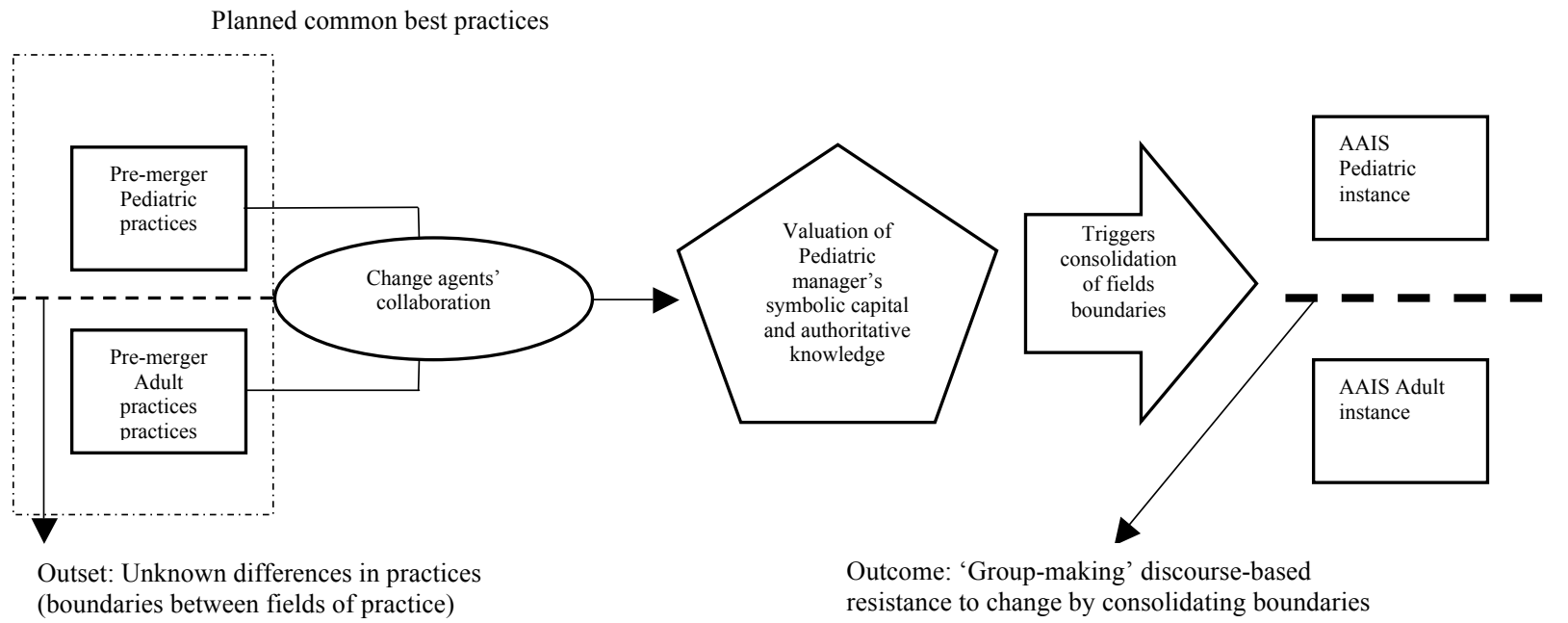

Figure 1: The process of boundary consolidation 
"I would say we [Adult centers] are now reaching the point of blend I suppose because we're trying to take best practice from each center [adult] and putting it together [...], but as far as I'm aware, the Pediatric is standalone" (IS manager)

\section{Discussion}

We report the findings of a case study of an IS implementation project aimed at unifying the ambulatory practices of a large healthcare center that resulted from the merging of three hospitals and supporting them with a unique, mutual information system. In this project, three department managers were appointed as center-based team leaders and nominated as change agents and boundary spanners. The case focuses on the interactions between the three managers and specifically shows how one of the department managers, the Pediatric manager, successfully used her symbolic capital to make claims of authoritative knowledge. This in term led to the consolidation of pre-merger boundaries and legitimized the exclusion of her department from the merging exercise.

This boundary reinforcement represents an unintended outcome of an intended organizational change imposed by a merger. The Pediatric manager instead of acting as a change agent actually acted as a boundary consolidator by engaging in discourses of authoritative knowledge [25], and 'group-making' [3] that facilitated her actions. Based on symbolic discourses, boundary consolidation represents a means for resisting the change brought in by a merger. The two discourses represent the basis for making claims about specific actions of boundary spanners. While these discourses are not specific to an organizational context, the events that triggered them in our case study are specific to a post-merger integration environment.

These symbolic discourses were necessary for the Pediatric manager to represent her field of practice during the struggle over classifying the Pediatric center as being unique and its environment not being ready to be included within the MHC. The existence of a relationship between the Pediatric manager's discursive strategy and her use of the accumulated symbolic capital pointed to the fact that the Pediatric manager pursued not only individual, but also collective interests to resist the change in practices. The Pediatric manager's collective representations inculcated the reality of the existing boundaries between the Pediatric center and the Adult centers as something that could not be changed during the process of system implementation. It also threatened to trigger "power dynamics that undermine collaboration" [19, p. 310]. The Pediatric manager mixed symbolic group-making and claims of relevant knowledge that skewed the existing power dynamics within the project team and helped her justify the way the system was configured (reflecting pediatric center pre-merger practices).

\subsection{Contribution \#1: Change agent as resistor}

By addressing the boundary spanning literature, the main contribution of this study relates to the theoretical development of a practice perspectivebased discursive analysis of the outcomes of a crossboundary IS integration process in a PMI context, which includes the concept of boundary consolidation. The Pediatric manager illustrates what Levina and Vaast [18, p. 356] describe as a boundary spanner with symbolic capital who deliberately "fails to develop an interest in developing a new joint field". The actions of the Pediatric manager suggest that sometimes change agents use their symbolic capital to reinforce existing boundaries and obstruct boundary spanning, when personal or local interests are at stake. Thus, instead of being an agent that promotes change, the agent reinforces existing boundaries. Boundary reinforcement or consolidation encompasses the ways in which an individual, member of a professional community (in our case a field of practice) internally sets and reclaims its boundaries by increasing member awareness of boundaries and emphasizing community identity [11].

In the AAIS study, the Pediatric manager, who was mandated by the MHC upper management to implement PMI changes and remove boundaries for collaboration by bridging cognitive and knowledge gaps across the pre-merger boundaries, did exactly the opposite by reinforcing the fences between the Adult centers and the Pediatric center. Indeed, instead of focusing on commonalities and dependencies between the three sites, the Pediatric manager's efforts and energy were invested in highlighting the differences (e.g. children vs. adult patients, no information exchange between the Pediatric and the Adult centers) as well as the uniqueness of the Pediatric center (e.g. in terms of procedures, clerical tasks, etc.). The Pediatric manager's forerunner attitude as well as her legitimacy, based on her charisma, her experience and her reputation, enabled her to mobilize support around the idea that the Pediatric center on one side and the Adult centers on the other, had different ways of working and required different AAIS. She was able, through her authoritative knowledge and 'group-making' 
discourses, to redefine the "initial" strategic rationale of the AAIS and alter the project team's reality by causing the project to deviate from its original objective of an integrated system to finally end up with the development of two separated AAIS. Thus, the Pediatric manager did not play the change agent role as it would have initially been expected by the upper management, but a boundary consolidator one.

As a result of the actions of the Pediatric manager, the practices of the Pediatric hospital center remained resistant to change. Earlier research has suggested that suggested that change agents may inhibit wider adoption of a new system that would facilitate change of practices [22], since potential users perceive the new system as "for nominated boundary spanners to decide how to use" rather than "for everybody to use" [18, p. 357]. Rivard and Lapointe [21] proposed a taxonomy of responses which could be used to react to resistance: 1) Inaction (unawareness, deliberate ignorance, and impotence), 2) Acknowledgement, 3) Rectification (congruent vs. non-congruent) and 4) Dissuasion (coercion, authoritative persuasion, supportive persuasion). However, in the AAIS case study, the Pediatric manager used discursive strategies akin to some of the responses proposed by Rivard and Lapointe [21], not to react to resistance, but to consolidate the boundaries between the Adult and Pediatric fields of practice. Indeed, the Pediatric manager through various discursive strategies, tried to modify the project's initial strategic rationale by highlighting the differences between the fields of practice and persuade the rest of the project team that the project outcome would be better represented by two separated systems. Such strategies are similar to the non-congruent rectification and persuasion responses proposed by Rivard and Lapointe [21]. Thus, in our study we found that the Pediatric manager instead of using her symbolic capital to diminish boundaries, she strengthened them by acting as a boundary consolidator.

\subsection{Contribution \#2: The Role of Symbolic Capital in Consolidating Boundaries}

Empirically, this paper enhances our understanding of discursive legitimation during the process of PMI by identifying two symbolic discourses, authoritative knowledge and 'group-making' that lead to the reinforcement of the pre-merger boundaries in the case of the Pediatric center. Our study also suggests that in a specific context such as mergers, some change agents will use their individual capital to interfere with planned change by engaging in legitimation discourses to consolidate existing boundaries.

In the AAIS case study, the Pediatric manager used her symbolic capital and took advantage of the fact that the first beta testing to configure the AISS was implemented at the Pediatric center, to submit change requests to adjust/modify the software package's functionalities. These changes were meant to reflect Pediatric center's pre-merger practices without considering the Adult centers' contexts and specific needs. These change requests were part of the Pediatric manager's discursive strategies to separate the Pediatric ambulatory practices from the rest of the MHC. One possible explanation of Pediatric manager playing the role of a boundary consolidator may stem from the fact that she was simultaneously playing two opposing roles. As a member of the project team, she played a change agent role; individuals "responsible for identifying the need for change, creating a vision and specifying a desired outcome, and then making it happen" [12, p. 362] and, as the ambulatory service manager, she played a change recipient role; individuals "who are responsible for implementing, adopting, or adapting to the change(s)." [12, p. 362]. The Pediatric manager was both the implementer and the recipient of change. As a change agent, she was formally designated to implement the PMI changes and ensure that the potential turbulences caused by such major organizational change would not affect the main goal of the project, that is, having a cross-boundary integrated system. However, as a change recipient, she was responsible to adapt the new practices imposed by the new AAIS on the Pediatric ambulatory service as well as minimize the prospective disruptions brought to the Pediatric local practices. To do so, the Pediatric manager used her symbolic capital and various discursive strategies to demonstrate that, the Pediatric center was different and that status quo should be maintained. Thus, it is possible that her dual status might have helped her consolidate the boundaries around the Pediatric center.

\subsection{Contribution \#3: Strategies to Consolidate Boundaries}

Our study enriches the existing explanations of how and why intended strategies sometimes lead to unintended consequences [1]. Research drawing on socio-cognitive theories had already examined the role of social interactions [7] and past experience as sources of collective understanding, which may ultimately affect the outcome of an organizational change [32]. These theories contend that individuals' 
thoughts about IT-led change are not formed in isolation but based on collectively shared understandings of what the technology is or how the technology can affect their practices. In this sense, Balogun and Johnson [1] suggest that unanticipated consequences are the result of organizational actors creating mental frameworks of references useful for the interpretation of reality through social interactions. In the AAIS case study, one strategy used by the Pediatric manager to alter the project team's mental framework was by voicing issues [8].

An issue is a "subjective 'chunk of knowledge' enacted by a stakeholder in a particular place and time within the project" [30, p. 46] and can be conceptualized as "knowledge at a boundary". Issues can also be considered as vehicle for knowledge transfer, transaction and transformation, which will affect boundaries. Issues that have high levels of commonality and dependency between stakeholders should weaken boundaries whereas issues with low levels of commonality and dependencies should consolidate boundaries [30]. Also, as issues are intertwined with the stakeholders' legitimacy and symbolic capital, some of them will have more influence than others. In the AAIS project, the Pediatric manager relied on her symbolic capital to ensure that the issues that she voiced would be considered as authoritative knowledge. She also voiced issues that would minimize the possible commonalities between the Pediatric center's practices and those of the Adult centers' in order to consolidate the boundaries between the three MHC sites. Thus, our study provides a practice lens and an issue management perspective on why and how social processes of interaction between managers engaged in making sense of intended changes may lead to unintended outcomes.

\section{Conclusion and Limitations}

This study examines the practices of appointed change agents in a PMI cross-boundary IS implementation project and highlights their use of influence tactics to promote or resist change. We show that when personal or local interests are at stake, sometimes change agents use their symbolic capital to reinforce existing boundaries and obstruct boundary spanning. The process is based on other actors' valuation of the change agent's symbolic capital and authoritative knowledge, something which may serve to legitimize boundary consolidation instead of boundary spanning. Thus, instead of being an agent that promotes change, the agent reinforces existing boundaries. As such, this study extends previous studies on boundary spanning [18] by introducing the concept of boundary consolidation and adds to the existing explanations of how intended strategies sometimes lead to unintended consequences [1]. The case study also provides rich data documenting the challenges organizations face when they try to merge fields of practice and support them with a common information system.

The main limitation of this study might be that it attempts at generalizing only from empirical statements to theoretical statements from a case study [17]. However, it has been shown that statistical, sampling-based generalizability may be an unsuitable goal for qualitative studies [6]. The MHC case is built on a strong historical foundation and deals with issues of central importance to our research which makes it purposeful. Learning from this case can now be transferred to other contexts for further refinements that eventually will offer statistical generalizability. Looking at industry level data and data from other settings may help overcome this limitation and provide new understandings.

The theoretical explanation offered here opens up avenues for more in-depth explorations of some of the more complex processes associated with the dynamic relationship between the change agents and IT-enabled organizational change. Future studies should assess in more depth how the actors involved in cross-boundaries IS projects interact and how the nature of these interactions affects the outcomes of the projects. In this vein, an explanatory-based theorization by identifying social mechanisms, that is processes composed of actions, events and "chains or aggregations of actors confronting problem situations and mobilizing more or less habitual responses" [13, p. 368], would explain the intermediate events that would partially influence the evolution from an initial state of a phenomenon to a final observed outcome.

\section{Acknowledgements}

The authors would like to gratefully acknowledge the Canadian federal SSHRC funding (\#430-20180351) received for this project.

\section{References}

1. Balogun, J. and Johnson, G., "From Intended Strategies to Unintended Outcomes: The Impact of Change Recipient Sensemaking", Organization Studies (26:11), 2005, pp.1573-1601.

2. Bourdieu, P., Outline of a Theory of Practice. (Esquisse d'une Théorie de la Pratique). Translation by R. Nice, Cambridge University Press, 1977. 
3. Bourdieu, P., "What Makes a Social Class? On the Theoretical and Practical Existence of Groups," Berkeley Journal of Sociology (32), 1987, pp. 1-17.

4. Brown, J. S., and Duguid, P., "Knowledge and Organization: A Social-Practice Perspective," Organization Science (12:2), 2001, pp. 198-213.

5. Carlile, P. R., "A Pragmatic View of Knowledge and Boundaries: Boundary Objects in New Product Development," Organization Science (13:4), 2002, pp. 442-455.

6. Denzin, N. K., and Lincoln, Y. S., The Sage Handbook of Qualitative Research. Beverly Hills: SAGE, 2000.

7. Dulipovici, A. and Robey, D., "Strategic Alignment and Misalignment of Knowledge Management Systems: A Social Representation Perspective", Journal of Management Information Systems (29:4), 2013,pp. 103-126.

8. Dutton, J. E., and Ashford, S. J., "Selling Issues to Top Management", Academy of Management Review (18:3), 1993, pp. 397-428.

9. Eisenhardt, K. M., and Graebner, M. E., "Theory Building from Cases: Opportunities and Challenges," Academy of Management Journal (50:1), 2007, pp. 25-32.

10. Empson, L., "Fear of Exploitation and Fear of Contamination: Impediments to Knowledge Transfer in Mergers between Professional Service Firms," Human Relations (54:7), 2001, pp. 839-862.

11. Faraj, S., and Yan, A., "Boundary Work in Knowledge Teams," Journal of Applied Psychology (94:3), 2009, pp. 604-617.

12. Ford, J. D., Ford, L. W., and D'Amelio, A., "Resistance to Change: The Rest of the Story", Academy of Management. The Academy of Management Review, (33:2), 2009, pp. 36-52

13. Gross, N., "A Pragmatist Theory of Social Mechanisms", American Sociological Review, (74:3), 2009, pp. 358-379.

14. Hartley, J., Benington, J., and Binns, P., "Researching the Roles of Internal-Change Agents in the Management of Organizational Change," British Journal of Management (8:1), 1997, pp. 61-73.

15. Lamont, M., and Molnar, V., "The Study of Boundaries in the Social Sciences," Annual Review of Sociology (28), 2002, pp. 167-195.

16. Larsson, R., and Finkelstein, S., "Integrating Strategic, Organizational, and Human Resource Perspectives on Mergers and Acquisitions: A Case Survey of Synergy Realization," Organization Science (10:1), 1999, pp. 1-26.

17. Lee, A. S., and Baskerville, R. L., "Generalizing Generalizability in Information Systems Research," Information Systems Research (14:3), 2003, pp. 221243.

18. Levina, N., and Vaast, E., "The Emergence of Boundary Spanning Competence in Practice: Implications for Implementation and Use of Information Systems," MIS Quarterly (29:2), 2005, pp. 335-363.
19. Levina, N., and Vaast, E., "Innovating or Doing as Told? Status Differences and Overlapping Boundaries in Offshore Collaboration," MIS Quarterly (32:2), 2008, pp. 307-329.

20. Miles, M., Huberman, M., and Saldana, J., Qualitative Data Analysis, Beverly Hills: SAGE, 2013.

21. Rivard, S., and Lapointe, L., "Information Technology Implementers' Responses to User Resistance: Nature and Effects", MIS Quarterly (36:3), 2012, pp. 897-920.

22. Schultze, U., and Boland Jr, R. J., "Knowledge Management Technology and the Reproduction of Knowledge Work Practices," The Journal of Strategic Information Systems (9), 2000, pp. 193-212.

23. Scott, W. R., Organizations: Rational, Natural and Open Systems. Prentice-Hall, New Jersey, 1998.

24. Stahl, G., and Mendenhall, M. E., "Mergers and Acquisitions: Managing Culture and Human Resources," Organization Studies (26:10), 2005, pp. 1555-1559.

25. Suchman, L. A., "Practice-Based Design of Information Systems: Notes from the Hyperdeveloped World", The Information Society (18:2), 2002, pp. 139-144.

26. Tsoukas, H., and Chia, R., "On Organizational Becoming: Rethinking Organizational Change," Organization Science (13:5), 2002, pp. 567-582.

27. Vaara, E., "On the Discursive Construction of Success/Failure in Narratives of Post-Merger Integration," Organization Studies (23:2), 2002, pp. 211-248.

28. Vaara, E., and Monin, P., "A Recursive Perspective on Discursive Legitimation and Organizational Action in Mergers and Acquisitions," Organization Science (21:1), 2010, pp. 3-22.

29. Van Dick, R., Ullrich, J. and Tissington, P., "Working Under a Black Cloud: How to Sustain Identification after a Merger," British Journal of Management (17:S1), 2006, pp. S69-S79.

30. van Offenbeek, M. A., and Vos, J. F., "An Integrative Framework for Managing Project Issues Across Stakeholder Groups", International Journal of Project Management (34:1), 2016, pp. 44-57.

31. Vieru, D. and Rivard, S., "The Resilience of PreMerger Fields of Practice during Post-Merger Information Systems Development," International Journal of Technology and Human Interaction, (14:3), 2018, pp. 53-71.

32. Weick, K. E., "The Collapse of Sensemaking in Organizations: The Mann Gulch Disaster," Administrative Science Quarterly (38:4), 1993, pp. 628-652.

33. Yetton, P., Henningsson, S., and Bjorn-Andersen, N., "Ready to Acquire: The IT Resources Required for a Growth-by-acquisition Business Strategy," MIS Quarterly Executive (12:1), 2013, pp. 19-35. 